\title{
e-interview
}

\section{Ishtiaq Ahmad}

Ishtiaq Ahmad is an associate specialist in old age psychiatry with Birmingham and Solihull Mental Health Trust and Chairman of the Staff and Associate Specialist Psychiatrists Association. He trained at University College Dublin and at the University of Wales College of Medicine. His special interests include research on inadequacies of the Mental Health Act with respect to incapacitated adults.

What has been the greatest impact of your profession on you personally? Psychiatry has made me learn about the importance of interpersonal communication skills and to appreciate people's strengths, particularly in coping with enduring mental health problems.

\section{Do you feel stigmatised by your profession?}

On the contrary, I consider psychiatry to be a very interesting and thought-provoking field and I have found many people asking for advice in matters relating to every aspect of life.

What job gave you the most useful training experience?

My training period at St Vincent's Fairview in Dublin where I learnt interview techniques through video teaching with mock reality settings and was also involved in psychodynamic psychotherapy with Professor Michael Fitzgerald. Although I found psychodynamic principles very interesting, I was aware of their limitations, especially when applied to my chosen specialty of old age psychiatry.

\section{Which book/text has influenced you} most?

Law without Enforcement - Integrating Mental Health and Justice, edited by Nigel Eastman and Jill Peay (Hart Publishing, 1999). This book contains contributions by many distinguished authors and succinctly highlights different ethical, moral and legal dilemmas associated with current mental health legislation in the UK, and advances the 'effectiveness' debate.

What part of your work gives you the most satisfaction?

Working with caregivers and families to help them cope with enduring mental health problems, particularly dementia.

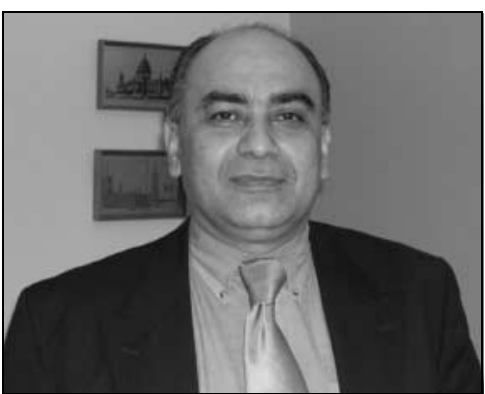

What are the main ethical problems that psychiatrists will face in the future?

As an old age psychiatrist, I can foresee the tremendous ethical dilemma psychiatrists might face when confronted with a situation where there is an advance directive in place that is in conflict with the law.

How would you improve clinical psychiatric training?

By getting people to recognise that it is not the number of degrees which make a good trainer! Equally, I cannot overemphasise the importance of having a good bedside manner.

What is the most promising opportunity facing the profession? The drive to embrace evidence-based practice.

What is the greatest threat? In the quest to fulfil targets and with the need for countless time-consuming form filling, clinicians might lose the ability to take a basic history and become glorified clerks!

What single change would substantially improve quality of care? Client-centred care, by which I mean taking into account the views of the patient and the families.

\section{What conflict of interest do you} encounter most often?

The ever-increasing reliance on the pharmaceutical industry in the organisation of local meetings for continuing professional development.

\section{Do you think psychiatry is brainless or} mindless?

I think that psychiatry is neither brainless nor mindless. There is no harm in considering alternative, different and varied approaches which might ultimately benefit our patients. As psychiatrists, we are in a privileged position to recognise the fallacies associated with this type of fruitless discussion

How would you entice more medical students into the profession?

By demonstrating the benefits of communication and interviewing skills and what psychiatry can offer them in this context.
What single change to mental health legislation would you like to see?

Legislation that respects patient autonomy and protects them from overintrusive measures, rules and regulations. College of Psychiatrists change? In my view, the College should be more inclusive and embrace all 'grades' of psychiatrists. Recently it has also been proposed that the College should consider changing its name to convey the idea of more openness. However, in the spirit and pursuit of openness, I would agree with other members that of other disciplines to step into the shoes of psychiatrists.

What is the future for psychotherapy in psychiatry training and practice? Traditional psychotherapy has its limitations and I believe that in this era of evidencebased practice it will be prudent to concentrate on effective strategies such as cognitive-behavioural psychotherapy.

\section{What single area of psychiatric} research should be given priority? Quite clearly dementia care needs to be researched with full vigour.

What single area of psychiatric practice is most in need of development?

Neuropsychiatry in terms of dementia.
How should the role of the Royal one should not underestimate the desire 